\title{
Meninas "Invisíveis"
}

\author{
A Realidade da Ressocialização das \\ Adolescentes na Cidade de São Paulo
}

Tatiana Lourenço Emmerich de SouzA

Universidade Federal do Rio de Janeiro

O artigo faz um estudo bibliográfico baseado no Relatório de Pesquisa do Conselho Nacional de Justiça (CNJ/2015), denominado "Dos espaços aos direitos: a realidade da ressocialização na aplicação das medidas socioeducativas de internação das adolescentes do sexo feminino em conflito com a lei nas cinco regiões". O objetivo é fazer uma análise crítica da atual realidade da ressocialização de meninas em conflito na cidade de São Paulo, visando a compreensão do dia a dia das adolescentes durante o cumprimento de medidas socioeducativas de internação, revelando também que por muitas vezes estas estão inseridas em unidades despreparadas para recebe-las, o que evidência a negligência do Estado frente as políticas públicas voltadas para as especificidades de gênero. Portanto é necessário uma reflexão sobre os discursos estigmatizastes na vida das adolescentes. Assim, devemos ressaltar que a política criminal tem como alicerces práticas cruéis, através da violência simbólica, para executar seu poder em camadas da população que geralmente são: as camadas mais pobres da população, negros, e mulheres. Assim, as meninas "invisíveis" sofrem diariamente com o racismo e preconceitos, tanto pela sociedade quanto pela própria lei que as "pune", já que passam por situação de discriminação pelo único fato de serem mulheres; evidenciando que o cometimento de atos infracionais pelas adolescentes e as medidas socioeducativas aplicadas, sobrepujam os limites impostos pelas leis aplicadas pelo judiciário.

Palabras Claves: Meninas. Internação. Socioeducação. São Paulo. Gênero. 


\section{Introdução}

O tema escolhido para o artigo: "Meninas "invisíveis": a realidade da ressocialização das adolescentes na cidade de São Paulo", teve inspiração nas aulas de Teorias Críticas dos Direito Humanos, da Faculdade Nacional de Direito (FND/UFRJ) pelo Mestrado do Programa de Pós Graduação em Políticas Públicas em Direitos Humanos (PPDH) da Universidade Federal do Rio de Janeiro(UFRJ).

A metodologia utilizada foi a bibliográfica, fazendo uma reunião das produções existentes sobre o tema, relacionando-a com o Relatório de Pesquisa do Conselho Nacional de Justiça (CNJ), realizado no ano de 2015 e, denominado "Dos espaços aos direitos: a realidade da ressocialização na aplicação das medidas socioeducativas de internação das adolescentes do sexo feminino em conflito com a lei nas cinco regiões".

O objetivo é fazer uma análise crítica da realidade da ressocialização de meninas em conflito com a lei na cidade de São Paulo, visando a compreensão do dia a dia das adolescentes durante o cumprimento de medidas socioeducativas de internação, revelando também que por muitas vezes estas estão inseridas em unidades totalmente despreparadas para recebe-las, o que evidência o negligenciamento do Estado para com as políticas públicas voltadas para as adolescentes e as especificidades de gênero.

Desta maneira, se faz necessário uma reflexão sobre os discursos estigmatizantes no começo da vida das adolescentes do sexo feminino em conflito com a lei. Neste momento, devemos ressaltar que a política criminal tem como alicerces o controle do estado, capitalista, que dissemina práticas violentas, através da violência simbólica, para executar seus poderes em camadas da população que geralmente são: as camadas mais pobres da população, negros, e mulheres.

Assim, podemos perceber que a institucionalização de crianças e adolescentes no Brasil é um movimento macróbio advindo das Roda dos Expostas, responsáveis pelo abrigo e recolhimento exclusivo para meninas. Destarte, pode - se entender que tanto antigamente nos recolhimentos, como também nas internações, basearam-se sempre em produções sexistas, que confirmam a diferença de gêneros e de estigmas.

As meninas "invisíveis" sofrem diariamente racismo, preconceitos e desigualdades sociais, tanto pela sociedade quanto pela 
própria lei que as "pune", já que passam por situação de discriminação pelo único fato de serem mulheres; evidenciando que o cometimento de atos infracionais pelas adolescentes e as medidas socioeducativas aplicadas, sobrepujam os limites impostos pelas leis aplicadas pelo judiciário.

Os estigmas multiplicam-se, o binômio lei - judiciário "punem" as adolescentes em conflito com a lei ao invés de ressocializar e as leis morais que controlam o comportamento de gênero fator institucionalizados pelo próprio Estado, que faz da análise crítica um ponto crucial para observação da realidade das meninas em conflito, deixando de lado a visão machista e patriarcal.

Desta forma, o trabalho se dividiu em três partes, para melhor compreensão da matéria; na primeira parte fazendo um breve panorama da situação geral de jovens em conflito com a lei, e em especial, a conjuntura das meninas internadas em unidades socioeducativas na cidade de São Paulo, traçando o perfil dessas adolescentes, bem como, revelando os ambientes de internação e a visão dos agentes da Fundação Casa frente a esse convívio.

Na segunda parte, uma breve exposição sobre a questão dos direitos individuais das adolescentes internadas, e como ficam as especificidades de gênero e a sexualidade dentro dessas unidades socioeducativas.

Na terceira parte, será feita uma análise crítica sobre a realidade das adolescentes em conflito com a lei frente um estudo bibliográfico que referente a matéria eletiva Teorias críticas dos Direitos Humanos, do curso de mestrado da UFRJ, referente a questão do feminismo feminismo frente as desigualdades e precariedades do sistema socioeducativo, principalmente frente a visão da filosofa e ativista Angela Davis.

\section{Panorama da situação de jovens no brasil e de meninas em conflito com a lei na cidade de São Paulo}

A criminalização de adolescentes em conflito com a Lei é um problema social que se perpetua ao longo da história brasileira, desde meados do século XIX, esses adolescentes em conflito eram 
denominados como menores delinquentes ou abandonados, que geralmente faziam parte das classes mais pobres da população, em famílias inseridas nos chamados "ambientes de marginalização", onde "maus hábitos" eram exercitados, como por exemplo, o uso de drogas, prostituição, e pequenos crimes.

$\mathrm{Na}$ realidade da época, ser um adolescente abandonado era motivo de ser enxergado pela sociedade como um menor delinquente, estes que ficavam em poder da polícia comum quando presos, e passavam pelo ritual das triagens autoritárias e subjetivas, que separavam os que ficariam reclusos dos que seriam devolvidos à família. Algumas outras medidas de "ressocialização" ficavam sob o controle de escolas militares e da igreja católica em função do conservadorismo do período.

Neste momento, foi criado o Código de menores em 1927 que abrangia em tese a proteção de crianças e adolescentes, bem como, sua correção para aqueles que infringiam leis penais, independentemente de classe, sexo, cor e religião. Porém, a situação não se modificou, já que os "menores" que se inseriam na norma eram os mesmos: menores delinquentes derivados de classes mais pobres, com pouco acesso à educação, geralmente negros, imersos em ambientes ditos como propensos a criminalidade.

Em pleno século XXI, a conjuntura não se modificou no que tange aos sujeitos a quem a norma iria ser aplicada, isto também se dá pelos processos de criminalização desses jovens como também da sujeição criminal, conforme aborda Misse (1999):

"Dados certos padrões de construção social da sujeição criminal, verifica-se uma constante conexão, na representação social, entre certas variáveis sociais e atributos de indivíduos incriminados por certos tipos de crimes. Essas variáveis comparecem seja nos tipos sociais em que eles se enquadrariam, seja na conexão explicativa entre o sentido social que se atribui a essas variáveis e a motivação que são atribuídas aos tipos (ou que eles incorporariam) para entrarem socioeconômica, cor, nacionalidade ou naturalidade, faixa etária, gênero, indicadores de filiação a uma regularidade de emprego e muitas outras dimensões (modo de se vestir, maneira de andar, modo de falar, expressões sociais de autocontrole) que servem socialmente para estratificar, diferenciar e construir estereótipos de identidades sociais são mobilizadas pela representação social para distinguir indivíduos suspeitos”. (MISSE, 1999). 
Em 1990, o sistema normativo brasileiro aprovou o Estatuto Criança e do Adolescente - (ECA - Lei 8.069/90), fruto do processo de redemocratização do país, que ocorreu no final da década de 80, onde foi modificado o exercício de poder no país, ou seja, o fim da ditadura militar, marcada pela doutrina da situação irregular, e inaugurando a fase democrática, onde foi implantando políticas em que crianças e adolescentes passariam a ser vistos como sujeitos de direitos.

O Estatuto da Criança e do Adolescente tentou reestabelecer a cidadania entre crianças e adolescentes, já que foi influenciado pela Convenção dos Direitos das Crianças da ONU de 1989, em que o Brasil foi o primeiro signatário em função de muitas denúncias de assassinatos de crianças e adolescentes durante este período. Esta convenção priorizava o desenvolvimento saudável de crianças e adolescentes tanto na esfera social quanto em sua individualidade, já que estes ainda estão em processo de formação de suas personalidades.

Durante mais de um século, a pobreza e a delinquência foram fundamentos para a intervenção de controle social e punitivo dos denominados "menores", que hoje, por força do ECA, são chamados de crianças e adolescentes. (SOUZA,2012)

Antigamente, a doutrina da situação irregular fazia com que o poder estatal, na figura do poder judiciário, atuasse como agente de controle das ações desses adolescentes em conflito com a Lei, onde se tinha apenas a intenção de punir através de um juiz tutelar. Trata-se da construção da chamada patologia social do irregular que categorizava pobres, negros, abandonados e delinquentes para o controle do Estado. (SOUZA,2012).

Com todo o aparato jurídico-normativo recém desenvolvido, acreditava-se que o não realizado no passado com a doutrina irregular fosse ser corrigido com ECA, porém, não foi o que aconteceu, já que a grande maioria dos adolescentes continuam em constante estado de violação de suas cidadanias pelo próprio Estado, que colocam-os como jovens criminalizados e vistos como inimigos sociais.

A desigualdade presente na sociedade brasileira é um dos fatores que perpetua esta situação, bem como, a falta de ensino público de qualidade, que alteram comportamentos, enfraquecem valores e tiram desses adolescentes suas opiniões críticas da realidade em que estão inseridos. Esses comportamentos são legitimados pelo poder simbólico do estado, onde os adolescentes não se opõem contra essa relação de 
poder, já que não se sentem vítimas, mas sim em uma situação inelutável e muitas vezes natural.

Em recente pesquisa do Núcleo de Criminologia da Universidade Candido Mendes (2012)1 ${ }^{1}$, foi constatado que a maioria desses adolescentes em conflito com a Lei são do sexo masculino, onde apenas $13 \%$ são do sexo feminino, e menos da metade estava assistido por parentes de $1^{\mathrm{O}}$ grau no momento da infração. Apenas $11 \%$ estavam devidamente matriculados nas escolas e $22 \%$ possuíam menos de 14 anos no momento do ato infracional, sendo que mais de $50 \%$, eram usuários de algum tipo de entorpecente.

Porém, um dado relevante foi que mais da metade desses jovens evadiram das medidas aplicadas, o que mostra que o sistema não está preparado para poder ressocializar crianças e adolescentes, sendo o Brasil parte de um regime fraco quanto às políticas públicas relativas ao sistema de reintegração à sociedade e de formação do jovem brasileiro. (SOUZA,2012).

Esses dados também são confirmados quando confrontados com a pesquisa realizada pelo Conselho Nacional de Justiça - CNJ em 2012², que chegou à conclusão de que, a cada dez adolescentes que cumprem medidas socioeducativas em estabelecimentos com restrição de liberdade, quatro são reincidentes, e ainda identificou um percentual de reincidência altíssimo quando se buscou os 14.613 processos de execução de medida socioeducativa, onde a reincidência chegou a 54\% dos casos.

O levantamento aponta ainda, entre outros dados, que $57 \%$ dos jovens entrevistados não frequentavam a escola antes de ingressar na unidade. A tortura e os maus- tratos são denunciados na seguinte ordem: 28\% dos entrevistados declararam ter sofrido algum tipo de agressão física por parte dos funcionários, $10 \%$ pela Polícia Militar, após o ingresso na unidade, e $19 \%$ afirmaram serem alvo de castigo físico durante a internação.

1 Investigação acadêmica realizada pelo grupo de pesquisadores formado em 2012, na Universidade Candido Mendes, Campus Centro, para executar o Projeto de Pesquisa sobre o tema análise do discurso nas sentenças judiciais sobre Ato Infracional publicada na Revista de Direito da UCAM, $\mathrm{n}^{0} 18$ do ano de 2013.

2 Pesquisa realizada pelo CNJ no ano de 2012 e denominada Panorama Nacional Execução de medidas de socioeducativas de internação http://www.cnj.jus.br/images/programas/ justica-ao-jovem/panorama_nacional_justica_ao_jovem.pdf 
Outra pesquisa também realizada no ano de 2012, denominada de Mapa da Violência3, do Centro Brasileiro de Estudos Latinos Americanos, FLACSO BRASIL, conclui que as taxas de homicídios contra crianças e adolescentes cresceram 346\% entre 1980 e 2010, vitimando 176.044 crianças e adolescentes durante trinta anos, entre as maiores vítimas crianças e adolescentes do sexo feminino, confirmando que não ocorreram melhoras significativas neste assunto mesmo com o advento do ECA e nem em relação à questão de gênero.

O que podemos perceber é que as normas do ECA se enfraquecem quando associadas a um Estado de Direito superficial, marcado por normas jurídicas maquiadoras e sem efetividade, uma vez, que não existe investimento em ações que nos remetam a políticas públicas atuantes, capazes de transformar e reestabelecer direitos violados ou capazes de ressocializar adolescentes em conflito com a Lei, um exemplo disso, é que a maioria desses adolescentes em conflito com a lei praticaram crimes análogos ao de tráfico de drogas e de roubo, segundo a pesquisa do Núcleo de Criminologia da Universidade Candido Medes (2012).

Desta forma, é possível perceber a amplitude do problema e a real emergência de métodos preventivos, para que se possa estagnar os processos de criminalização, revelando a estes "menores" novas possibilidades fora do mundo do "crime". Destarte, as políticas públicas promovidas tanto pelo Estado como por organizações não governamentais, são essenciais para que esses adolescentes em conflito com a lei saiam do processo de criminalização em foram inseridos pelo próprio Estado, só desta maneira será possível a ressocialização e a promoção de educação para que estes possam ter novos futuros.

Assim, o que podemos verificar é que o Estado que promove mais políticas de internação do que programas que aceleram o processo de afirmação de direitos básicos (educação, saúde, profissionalização, arte, cultura e lazer), isso demonstra características de um sistema, assistido pelo poder judiciário, que abusa do poder punitivo estatal ao invés de afastar a punição, esta que deveria ser substituída por direitos que foram reprimidos durante a maior parte da vida desses adolescentes em conflito com a lei.

3 Panorama da evolução da violência dirigida contra os jovens no período compreendido entre 1980 e 2011, analisando os dados de Estados, Capitais e Municípios, aprofundando nas questões de gênero e de raça/cor das vítimas. http://www.mapadaviolencia.org.br/pdf2013/ mapa2013_homicidios_juventude.pdf 
Logo, seria possível um fortalecimento da efetividade das normas do ECA, principalmente as referente as medidas socioeducativas, estas que também precisam passar por critérios de avaliação na hora de sua aplicação, uma vez que muitos juízes seguem um padrão de características subjetivas do adolescente (cor, sexo, condição social) para aplicar a "sanção", ao contrário de olhar para o caso em particular.

Isso demonstra claramente o porquê da não efetividade de medidas de ressocialização previstas no ECA. A mudança deve começar entendendo que esses atos infracionais além de serem fatos recebidos por nosso sistema jurídico, no que tange a "punição", são também fenômenos político-sociais, que lidam com jovens em processo de construção de suas personalidades. Isto posto, se faz necessário a mudança de objeto, ou seja, não só punir o fato, mas entender o que motivou o adolescente a cometer tal ato infracional, atacando os principais fatores de risco e substituindo estes por outros fatores ligados a proteção dos adolescentes. Só assim será possível ter efetividade das medidas socioeducativas e resgatar adolescente mostrando-lhes novas oportunidades que não as do "mundo da criminalidade".

O Relatório de Pesquisa do Conselho Nacional de Justiça (CNJ), realizado no ano de 2015, e, denominado "Dos espaços aos direitos: a realidade da ressocialização na aplicação das medidas socioeducativas de internação das adolescentes do sexo feminino em conflito com a lei nas cinco regiões', revela que essas meninas são aproximadamente $4 \%$ do total de adolescentes internados.

O que chama atenção é que suas carências e demandas de necessidades especiais, recebem nenhuma ou pouca atenção. Segundo Luís Geraldo Lanfredi, coordenador na área de medidas educativas para adolescentes em conflito com a lei do CNJ:

"Não há estabelecimentos adequados, estrutura física nem recursos especializados para o atendimento dessas adolescentes, seja porque o número de meninas internadas é menor, seja porque elas, em geral, não criam muitos problemas".

A realidade das unidades de internação feminina na cidade de São Paulo, estado brasileiro que mais possui centros de internação, não é diferente, muitas vezes acabam por ser piores do que a internação masculina, já que, as meninas demandam de cuidados especiais, por exemplo, maternidade e espaços de amamentação, que as unidades não possuem, e, quando tem, não dispõem de estrutura adequada. Isso 
também é um fator que exclui e perpetua desigualdades de gêneros dentro do sistema socioeducativo.

\subsection{Perfil das Adolescentes}

Segundo Relatório de Pesquisa do Conselho Nacional de Justiça (CNJ), realizado no ano de 2015, e, denominado "Dos espaços aos direitos: a realidade da ressocialização na aplicação das medidas socioeducativas de internação das adolescentes do sexo feminino em conflito com a lei nas cinco regiões', traçar o perfil das adolescentes é fundamental para entender a história dessas meninas até chegarem aos sistemas socioeducativos.

Outro fator relevante em se pesquisar o perfil, é a possibilidade de se compreender a questão da seletividade da justiça juvenil brasileira, que institucionaliza grupos sociais mais vulneráveis para o ingresso dentro dos sistemas de socioeducação, fazendo com que o Estado possua mais controle através de seu poder ou violência simbólica.

No caso das meninas, é possível perceber que a vulnerabilidade ultrapassa a questão econômica, já que é evidente o negligenciamento do Estado em relação as políticas públicas voltadas para as adolescentes e as especificidades de gênero, revelando que desde sempre as instituições de cumprimento de medidas se basearam em construções sexistas, reafirmando a distinção de gênero e de estigmas.

O que foi possível perceber é que a maioria das adolescentes em conflito com a lei na cidade de São Paulo possuem entre 15 a 17 anos de idade, onde $72 \%$ dos casos são da cor não branca (descrição dada pela propria pesquisa), $88 \%$ estão na primeira passagem pelo sistema de internação, com renda familiar não identificada e ensino fundamental incompleto.

Os atos infracionais mais cometidos por elas são crimes análogos ao tráfico de drogas e de roubo, representando $43 \%$ e $34 \%$ dos casos respectivamente. Esses dados se assemelham ao sistema prisional de adultos, como observa Olga Espinoza (2004, p.92): "O crime de maior incidência entre as mulheres presas é o tráfico de entorpecentes."

Isso acontece por não ocuparem lugares de liderança na cadeia criminosa do tráfico, conforme Relatório Final da Secretaria de Políticas Para as Mulheres do Ministério da Justiça (2008). Segundo o relatório 
do CNJ (2015), abordado neste trabalho, em São Paulo os crimes análogos ao tráfico de drogas cometidos pelas adolescentes em conflito possuem duas motivações: 1) independência financeira e 2) infração que não requer o emprego de violência. No trecho abaixo é possível verificar exatamente essa situação:

"F2 - Menina de 14 anos falando: “Ah, não, é porque eu tava com meu marido e aí a polícia veio e tal! Não podia me sustentar, tinha que fazer alguma coisa..." A grande maioria é tráfico [...] um delito considerado assim: "ah, é contra lei, mas eu não tô sendo violenta com ninguém! Eu tô vendendo, eu tô fazendo os meus contatos" Então é uma postura muito mais, assim, emocional e não tanto violenta."

Sobre o estado civil das meninas, o SINASE se mostrou ineficiente, já que não conseguiu diferenciar meninas solteiras das "casadas" ou namorando. Esse é um fator relevante, quando abordamos a questão da sexualidade e o direito de visitação íntima, uma vez, que as meninas internadas não possuem liberdade sexual e o nem direito de serem mães no período de cumprimento de medidas socioeducativas, diferentemente da situação dos meninos em conflito com a lei.

Um dado interessante que nos remete a análise crítica, é que na maioria dos PIAS4 investigados na pesquisa não haviam identificação de informações sobre a cor/raça/etnia das adolescentes, o que nos leva a acreditar em uma generalização daquelas que ingressam ao sistema, que é todo pensado na lógica masculina. Em relação a localização das instituições de cumprimento de medida foi possível perceber que a maioria delas estão centralizadas na capital do estado, que dificulta muitas vezes a visitação e a proximidade com a família, desrespeitando os princípios do ECA do artigo 124, inciso VI5 bem como, o artigo 35, inciso IX ${ }^{6}$ do SINASE.

4 Sistema Nacional de Atendimento Socioeducativo.

5 Art. 124. São direitos do adolescente privado de liberdade, entre outros, os seguintes: VI permanecer internado na mesma localidade ou naquela mais próxima ao domicílio de seus pais ou responsável.

6 Art. 35. A execução das medidas socioeducativas reger-se-á pelos seguintes princípios: IX fortalecimento dos vínculos familiares e comunitários no processo socioeducativo. 


\title{
2.2 Condições de Internação
}

Segundo o artigo 123 do Estatuto da Criança e do Adolescente ECA7 a internação deverá ser cumprida em entidade exclusiva para adolescentes, em local distinto daquele destinado ao abrigo, obedecida rigorosa separação por critérios de idade, compleição física e gravidade da infração, onde deverão também ter de cunho obrigatório atividades pedagógicas.

O SINASE em seu artigo $16^{8}$, também abordou que a estrutura física das unidades devem ser compatível com as normas estabelecidas pelo mesmo, onde é vedada a edificação de unidades socioeducacionais em espaços contíguos, anexos, ou de qualquer outra forma integrados a estabelecimentos penais.

Em São Paulo, o estado que mais possui instituições de cumprimento de medida para meninas, hoje possui duas unidades de internação feminina, que são regidas pela Fundação Casa e vinculados a Secretaria de Estado da Justiça e Defesa da Cidadania. A organização da Fundação Casa é bem peculiar, pois possui divisões complexas se assemelhando a redes de atendimento, já que hoje em dia contam com 150 casas, onde apenas 11 correspondem aos serviços oferecidos às adolescentes do sexo feminino e se subdividem em centros de atendimento, como mostra a tabela abaixo:

\section{Tabela 1 - Divisão das Casas na Cidade de São Paulo}
a) Centro de Atendimento Inicial (art. 175 do ECA)
b) Centro de Internação Provisória (art. 108 do ECA)
c) Casas de Semiliberdade (art. 120 do ECA)

\begin{abstract}
7 Art. 123. A internação deverá ser cumprida em entidade exclusiva para adolescentes, em local distinto daquele destinado ao abrigo, obedecida rigorosa separação por critérios de idade, compleição física e gravidade da infração. Parágrafo único. Durante o período de internação, inclusive provisória, serão obrigatórias atividades pedagógicas.

8 Art. 16. A estrutura física da unidade deverá ser compatível com as normas de referência do Sinase. § 10 É vedada a edificação de unidades socioeducacionais em espaços contíguos, anexos, ou de qualquer outra forma integrados a estabelecimentos penais. § 20 A direção da unidade adotará, em caráter excepcional, medidas para proteção do interno em casos de risco à sua integridade física, à sua vida, ou à de outrem, comunicando, de imediato, seu defensor e o Ministério Público.
\end{abstract}


d) Casas de Internação (art. 122)

População total de meninas no Sistema: Segundo o Serviço de Atendimento ao Cidadão (SAC, em março de 2013, a população adolescente do sexo feminino é de aproximadamente 386 adolescentes, onde 60\% deste total estão em casas de int ernação.

As casas de internação de meninas ficam sob a responsabilidade das Casas Chiquinha Gonzaga e Parada de Taipas, ambas com uma estrutura de muros altos, que se assemelham a prisões, e em nada demonstram ser ambientes propícios para a socioeducação. Geralmente possuem salas de aulas pouco iluminadas e com policias fazendo a segurança, segundo a pesquisa do CNJ de 2015: "com duas pessoas de segurança, uma janela de vidro aparentemente à prova de balas e duas portas pesadas com trancas liberadas após a entrada autorizada numa comunicação que ocorre por telefone."

Dentro das unidades, todas possuem refeitórios, salas de aulas, banheiros, estes que não possuem uma divisão, fazendo com que as meninas tenham que tomar banho vendo umas às outras. Apenas a unidade Chiquinha Gonzaga possui um prédio para atender as adolescentes grávidas ou no período pós maternidade denominada de PAMI, segundo a pesquisa do CNJ de 2015: "Também há um refeitório onde ficam as geladeiras (com cadeados) e o micro-ondas. É para lá que levam as refeições, que são comidas à mesa, respeitando uma ordem para se servirem, com bastante cautela."

Mesmo as grávidas, é possível perceber que as adolescentes internadas sofrem com o tratamento autoritário imposto dentro das unidades, que por muitas vezes não oferece dignidade as futuras mães, visto ao relato citado a cima onde as geladeiras da unidade ficam trancadas com cadeados, podendo comer apenas em horários específicos.

Dentro das unidades é comum ser fornecido as adolescentes o ensino médio formal regular e profissionalizante, onde a educação é influenciado por ideologias neoliberais, que assumem o controle através de uma falsa esperança de colocar a educação como prioridade, desta maneira o Estado mantém o discurso da cultura dominante, 
naturalizando desigualdades que justificariam o abandono estatal dessas adolescente.

No casos das adolescentes em conflito com a lei, a situação não se mostra diferente, mesmo o ECA garantindo no artigo 124: "receber escolarização e profissionalização", a situação não foi alterada, perpetuando a desigualdade social e econômica, já que dentro das instituições socioeducativas a educação se mostra precária, não sendo um dos objetivos principais da ressocialização, já que quem está ali não possui condições de "adquirir" educação segundo a forma neoliberal, revelando o caráter punitivo das medidas socioeducativas.

Sem a educação adequada, as adolescentes não conseguem a inserção no "novo" mundo que vai recebe-las após cumprimento das medidas, fazendo com que busquem outras formas de sobreviverem, através de atividades muitas vezes ilícitas, o que acaba por reinseri-las dentro do sistema socioeducativo. A questão educacional das adolescentes em conflito com lei na região sudeste, especificamente em São Paulo, é uma dificuldade real que as impede de ingressar no mercado formal, de maneira que estejam realmente preparadas para enfrentar o elevado o nível de exigência de escolarização.

\subsection{Visão dos Agentes sobre as Adolescentes}

Outro ponto interessante ressaltado na pesquisa do CNJ de 2015 , foi a visão das meninas sob a óptica dos agentes lotados dentro das unidades de internação, a maioria deles revela a diversidade de perfil, geralmente não violento e muito infantilizado, assim como a fragilidade das adolescentes, constatados pela vulnerabilidade econômica, estrutura familiar abalada e falta de referências positivas, que por muitas vezes acabam sendo ocupadas por referências de pessoas envolvidas com ilícitos, como percebido abaixo:

"Eu acho que uma parte importante que determinou o ingresso delas aqui, não de todas, mas de uma parte significativa, foram os recursos da comunidade insuficientes para a juventude, entendeu? Então assim, ao invés de elas terem uma liderança interessante que pudesse conversar, botar argumentos, se comunicar, não tem isso. Os recursos que existem eles são muito pouco capacitados para se comunicar com o adolescente. E aí quem sobra são as pessoas da comunidade, que em geral é uma comunidade bem pobre. E aí são referências de pessoas 
que tem algum envolvimento com ilícito, né? E uso de drogas como uma forma de alívio (FEMININO SP)"

A carência afetiva também foi outro ponto abordado pelos agentes nas entrevistas, que revelaram que as adolescentes do sexo feminino recebem menos visitas do que os adolescentes do sexo masculino, tornando-as não só invisíveis perante o Estado mas também para sua família, podemos observar isso na fala dos agentes das unidades de internação feminina:

"Ah, é uma carência muito grande. Carência... familiar, é uma carência emocional... essa questão de muitas vezes, né? isso você pode perceber até entre as próprias meninas mesmo, a questão da homossexualidade nos centros. É uma coisa que é. elas lidam de forma mais tranquila que os meninos. Os meninos não aceitam de jeito nenhum. A própria carência afetiva que as meninas tem, né? e assim, eu acho que por conta disso, tem algumas meninas que até dá a impressão que elas não querem sair, porque se elas saírem, elas sabem que quando elas saírem elas vão ter um mundo diferente do que é a fundação. O mundo lá fora. Às vezes vão voltar pra o mesmo lugar que estava, com as mesmas pessoas que estavam e tem menina que fala assim "ah, eu não sei se vou conseguir me segurar...!” (Agente Feminino SP). Eu até, uma coisa que eu me surpreendo até hoje, como elas recebem pouca visita, né, e os meninos era assim muita visita, né que vinha, tal. Então assim, mas assim, quando vem é muito mais mãe mesmo, né, do que pai, minoria que tem pai, quando tem pai (Agente feminino SP)."

Os funcionários também retratam o desejo das meninas em obter bens materiais para a obtenção de status social, assim como, o cometimento de atos infracionais influenciados por seus companheiros, por muitas vezes motivo principal da pratica de atos análogos ao crime de tráfico de drogas, exemplificado no trecho a baixo:

"A maioria das meninas não é envolvida no crime, a maioria é meio laranja, entrou por causa do namorado, entrou porque dava dinheiro em muito interior aqui. Então assim elas falam, via as moças na porta buscar de carro, as meninas andavam com as roupas super bonitas, daí elas me convidaram e eu fui por que eu queria as mesmas coisas. A maioria é por consumismo, o desejo de ter coisas (feminino, SP - f2). As meninas o que a gente percebe é elas são usadas, ela quase nunca vem sozinha, quase nunca elas estão no B.O. (boletim de ocorrência) sozinhas, elas quase sempre estão acompanhadas por um maior ou com um namorado, muitas são com o namorado, pelas próprias pessoas da família às vezes, já têm outras pessoas que estão complicadas com o tráfico (feminino, $\mathrm{sp}-\mathrm{f}_{4}$ ).” 
Assim, foi possível concluir que pela pesquisa do CNJ de 2015, os funcionários das unidades de internação feminina, as veem como crianças com diversos graus de fragilidades, e que seus atos infracionais não são cometidos pela personalidade violenta das meninas e sim pelas circunstâncias externas em que estão inseridas, ou seja, pela dura realidade das meninas pautadas pela desigualdade social, econômica, familiar e de gênero. Mesmo assim, não são todos os funcionários da Fundação Casa que possuem essa visão, e ainda tratam essas meninas como pessoas que oferecem perigo e medo, desta maneira são tratadas como inimigas sociais.

\section{Direitos individuais, gênero e sexualidade dentro dos centros de internação}

Os direitos individuais segundo José Afonso da Silva (2015): "são direitos fundamentais do homem - indivíduo, que reconhece a autonomia dos particulares, garantindo a iniciativa e independência aos indivíduos diante os demais membros da sociedade política e do próprio estado."

Geralmente são aqueles enunciados no artigo $5^{\circ}$ e seus incisos da $\mathrm{CRFB} / 88$, que asseguram a inviolabilidade do direito à vida, a saúde, educação e também de igualdade entre homens e mulheres etc. No caso de crianças e adolescentes em conflitos com a lei, especialmente as meninas, esses direitos individuais são assegurados tanto no ECA, pelo artigo 124 e incisos, como nos artigos do Sistema Nacional de Atendimento Socioeducativo (SINASE).

Porém, na maioria das vezes não são respeitados, no caso das adolescentes do sexo feminino, isso é ainda mais evidente, como constatou o relatório da pesquisa do CNJ de 2015. Abaixo, a tabela mostra alguns incisos do artigo 124 do ECA, que trata dos direitos individuais das adolescentes, e, quer constantemente são violados dentro das unidades de internação.

Tabela 2 -

Os Direitos individuais mais violados ques estão previstos no ECA

IX - Ter acesso aos objetos necessários à higiene e asseio pessoal;

$\mathrm{X}$ - Habitar alojamento em condições adequadas de higiene e salubridade; 
$\mathrm{V}$ - Ser tratado com respeito e dignidade;

VIPermanecer internado na mesma localidade ou naquela mais próxima ao domicíl io de seus pais ou responsável;

VII - receber visitas, ao menos, semanalmente;

VIII - corresponder-se com seus familiares e amigos;

Dentre as violações que foram constatadas pela pesquisa do CNJ com as meninas internadas em São Paulo, a primeira foi em relação a restrição alimentar das adolescentes, já que dentro das unidades não possui diversidade de alimentos. Isso faz com que as mesmas procurem cursos profissionalizantes de culinária, dentro das casas de cumprimento de medidas, para poder fazer/comer outros tipos de alimentos. Houve até um caso de restrição de água:

"Chamou atenção, no entanto, a declaração de duas adolescentes, as quais, quando discorriam a respeito do relacionamento conturbado das internas com alguns monitores (agentes socioeducativos), afirmaram dificuldades na obtenção de água: "É! Chegou de ter. Chegou de... teve um caso de monitor de negar água aí embaixo; outra é que é muito ignorante com as adolescentes!” (A1).”

Outra violação aos princípios basilares do ECA e do SINASE, no artigo $63, \S 2$, é sobre a questão da maternidade, uma vez, que é assegurado que mesmo a mãe estando em cumprimento de medida de internação, deve permanecer durante todo o período de amamentação com seu filho. Isso muitas vezes não acontece. Mesmo São Paulo possuindo o PAMI - Programa de Acompanhamento Materno Infantil, as adolescentes gestantes ou com filhos permanecem separadas das demais meninas internadas, e somente só continuam com seus filhos até eles completarem um ano de idade. Como mostra o trecho a baixo:

"As adolescentes informaram que é terminantemente proibida a comunicação entre as meninas das outras partes e mais especialmente com as meninas do Pami, porque as outras da internação regular seriam "más influências". Quando duas amigas são separadas dentro das turmas da internação regular, elas perdem o contato.”

A visitação estabelecida no artigo 67 do SINASE, também é outro direito constantemente violado, vale lembrar que as adolescentes já possuem um número bem menor de recebimento de visitas, se comparado com a internação masculina, e ainda contam com fatores de 
dificuldade financeira e de deslocação dos parentes até as unidades de internação, e algumas ainda revelam a revolta dos familiares com a internação, fator que os levam a não visitação das jovens. Essas questões nos levam a entender que os atos infracionais quando cometidos por mulheres são menos aceitos pela sociedade e ainda se mostram mais graves:

"Funcionário 3 -Adoro trabalhar com elas. Elas são, assim, emocionais, né? É... e... Assim, elas trazem mesmo, realmente, né? a rejeição aí duma sociedade, né? com relação à mulher. Então, a gente percebe, assim, que as meninas têm muito menos respaldo do que os meninos, né? Eu, até uma coisa que me surpreende até hoje como elas recebem pouca visita, né? E os meninos era, assim, muita visita, que vinha, tal."

Como se não bastasse, essas meninas invisíveis de São Paulo ainda passam pela não autorização/implantação das visitas íntimas nos centro de internação, direito também assegurado no artigo 68 do SINASE. Fato confirmado pelas adolescestes no trecho da entrevista do CNJ:

"P (pesquisador) - E seus parentes vem aqui te visitar? A2 (jovem) Vêm, todo domingo. P - Todo domingo eles vêm. E seu companheiro vem? A2 - Não, não pode. P - Não pode? A2 - Só família memo. P - E amigos podem vir visitar? A2 - Não.”

Em relação a gênero e sexualidade, foi possível perceber na pesquisa que é tema considerado "tabu", pouco falado nas unidades e assunto de controle. As meninas seguem sem visitação íntima de seus companheiros, sendo que muitas delas já iniciaram suas vidas sexuais. A privação da vida sexual da menina em conflito com a lei se mostra cruel, se comparado a unidades masculinas em que a visitação das parceiras é algo comum. Isso indica que a menina mulher não pode ter/dar continuidade a sua vida sexual, de forma livre, já que o sistema além de achar que a mulher não pode ter liberdade sexual, ainda usa isso como um controle de natalidade.

As relações homoafetivas dentro dos centros de internação também se mostram comuns, porém, de caráter transitório e proibido. $\mathrm{O}$ preconceito de funcionários em relação a esse tipo de comportamento das adolescentes se mostra presente e pouco aceito, vide trecho da entrevista do CNJ (2015), referente a pesquisa já mencionada neste trabalho: 
"P (pesquisador) - E você acha que essas meninas são discriminadas pelas outras, ou não? A1 (PE) - Acho que não. Tem umas que vêm pra cá e fala que não fica, e acaba ficando. $\mathrm{P}$ - Você acha que elas são descriminadas pelas demais meninas? A12 (SP) - Não. Sabe, só fala assim "Sapatão é tudo do demônio". P - Quem fala isso? A12 (SP) - As funcionária. P - As funcionárias falam? A12 (SP) - Fala: "Sapatão do caralho!” P - Funcionário, homem ou mulher? A12 (SP) - Homem. Em São Paulo, também se verifica essa vigilância: $P$ - Quais são essas normas? A7 (SP) - Ah, não pode ter sapataria, respeito a funcionário, na hora de comer, ficar em silêncio... A4 (SP) - Fica todo mundo junto e misturado. Os funcionários ficam dizendo que não pode conversar, porque é sapataria, não pode pegar na mão dessa menina, porque é sapataria... não pode conversar, uma assim na frente da outra. P - Não pode conversar? A4 (SP) - Não, porque eles dizem que é sapataria. P Mas quem fala isso? Os funcionários? A4 (SP) - Isso. Tem que ficar do lado dela conversando."

\section{Análise crítica da realidade das adolescentes em conflito e o feminismo}

A partir de 2003 houve a implantação da Política Nacional de Enfrentamento à Violência contra a Mulher, com a finalidade de prevenir violências de gênero, no caso, a combater/ proteger mulheres vítimas de qualquer tipo de violência face a seus agressores. Foi neste momento em que a mesma política nacional protegeu os direitos da mulher no cárcere, ou pelo menos tentou.

A tentativa de ser uma boa política pública, foi frustrada, uma vez, que nada foi dito em relação as meninas mulheres em conflito com a lei em cumprimento de medidas de internação. Esses centros de internação de adolescentes do sexo feminino podem ser comparados a prisões de mulheres adultas, em face de todo o negligenciamento estatal com suas necessidades e, também frente ao descaso social, político e econômico com essas meninas ainda em desenvolvimento.

Sobre a questão do cárcere, Davis (2000, p 523-531) aborda a semelhança das prisões femininas e à relação ao quanto é importante para os feminismos desvencilharem-se da noção de que há uma qualidade universal que podemos chamar de mulher:

"ANGELA: Se eu fosse tentar sintetizar as minhas impressões das visitas às prisões ao redor do mundo, e na sua maioria foram visitas a prisões femininas, incluindo três penitenciárias que visitei 
involuntariamente, teria de dizer que elas são sinistramente parecidas. Sempre me senti como se estivesse no mesmo lugar. Não importa o quão longe eu viajasse através do tempo e do espaço - de 1970 a 2000, e da Casa de Detenção feminina em Nova Iorque (onde eu mesma estive presa) até a prisão feminina em Brasília, Brasil -, não importa a distância, existe uma estranha similaridade nas prisões em geral, e especialmente nas prisões femininas. Essa mesmice das prisões femininas precisa ser avaliada com relação ao quanto é importante para os feminismos desvencilharem-se da noção de que há uma qualidade universal que podemos chamar de mulher. Isso me faz pensar no seu trabalho sobre o desafio de repensarmos as fronteiras entre as ciências sociais e as humanidades, como um meio de reflexão específica sobre as mulheres nas prisões.” (DAVIS, 2000)

Todo o desprezo com as adolescente é reflexo de uma sociedade machista e patriarcal, que esquece do papel da mulher na sociedade desde de seu processo de formação, como no caso das meninas, o que revela que o binômio proteção integral x direitos de gênero não andam juntos na infância e adolescência de meninas mulheres em desenvolvimento e, cumprindo medidas de internação.

A cultura de institucionalização no Brasil, desde o século XVIII, não visou a ressocialização de meninas para se tornarem mulheres independentes e livres, mas sim para se transformarem em mães ou donas de casa, e isso se perpetua até os dias de hoje, quando vemos dentro de unidades de internação cursos profissionalizantes apenas de culinária, ou regras que estimulem as meninas a cumprimento de tarefas domesticas, diferentemente dos centros de internação masculinos.

Desta maneira estimula-se o preconceito, uma vez que no caso de internação masculina se entende a raiva, e no caso feminino se repudia a histeria. Segundo Davis (2000, p 523-531):

"Poderíamos começar pensando sobre o modo estranho, mas previsível, com que o feminismo tem sido abraçado pelas hierarquias da custódia. (...)A demanda por mais guardas e oficiais femininas de alto nível tem sido complementada pela demanda em tratar da mesma forma prisioneiras e prisioneiros. Isso tem ocorrido à medida que departamentos de correção vão descobrindo que através da 'administração da diversidade' - incorporando homens de cor e mulheres de todas as raças - suas prisões se tornam mais eficientes. Desse modo, posições supostamente feministas apoiaram a tendência rumo a práticas mais repressivas de aprisionamento para mulheres e, especificamente, cabanas/campus para as fortalezas de concreto que estão sendo construídas hoje. Um exemplo interessante desse 
feminismo que demanda igualdade formal administradores de presídio de que as prisioneiras têm o direito de ser consideradas tão perigosas quanto os homens. Tekla Miller, ex-diretora da prisão feminina de Huron Valley, em Michigan, reclamou que o arsenal na prisão feminina era inferior ao das prisões masculinas, fazendo até mesmo um bem-sucedido lobby para o direito de atirar em prisioneiras que escapam.” (DAVIS, 2000)

O que se vê nos centros de internação, principalmente de São Paulo objeto de estudo, é o desempoderamento de meninas em desenvolvimento, e a criação de perfis fixos para o cumprimento de medidas socioeducativas: negras, "faveladas", de condição econômica baixa. Como vemos no trecho abaixo:

"P/ SP (pesquisador) - E que que aconteceu pra você ter desacatado o promotor, você quer falar um pouco sobre isso? A6 - Porque eu fugi do abrigo, aí eles falaram que era pra eu voltar e eu não voltei, fiquei um mês fora de casa, aí quando eu voltei eles falaram que o promotor queria falar comigo, só que ele começou a me desacatar, me tirar verbalmente, aí eu xinguei ele. $\mathrm{P}$ - Isso lá no abrigo ou em alguma audiência? A6 - No Fórum P - No fórum? A6 - No fórum. Ele falou que eu parecia uma favelada, uma Noia, falou um monte de coisa, aí eu fui lá e xinguei ele. P - Ele falou isso pra você? A6 - Falou. P - Você deve ter ficado bem brava né? A6 - Fiquei no ódio. P - E foi o mesmo promotor as três vezes? A6 - Foi. P - E o defensor que te ajudou foi o mesmo? A6 - Foi [...]”

Assim, a cultura do machismo também se revelou dentro desses sistemas socioeducativos, visto a falta de acervo de informações e pesquisa na área de jovens em conflito com a lei do sexo feminino, como disse Marília Montenegro de Mello Coordenadora da Pesquisa realizada pelo CNJ em 2015:

"Sobre as garotas, não havia nenhuma informação compilada. O sistema é todo pensado na lógica masculina", As internas não podem usar maquiagem nem esmalte, a não ser quando a direção autoriza, para algum dia especial. Se amarrarem as camisetas para lhes dar alguma personalidade, perdem tempo de banho de sol. Em alguns plantões, só podem sair dos quartos com o cabelo preso. São tratadas como quem oferece perigo. A disciplina se impõe. Elas se dirigem aos agentes, professores e seguranças como "senhor" ou "senhora". Dormem em quartos com mais de dez beliches, sem privacidade. Estão sempre em grupo e vigiadas." 
A questão de gênero, também é outro fator delicado dentro das unidades socioeducativas, deve-se ter uma preocupação em se desenvolver estudos de gêneros dentro das unidades de internação, visto a crescente absolutização das relações de poder de gênero e a carência de políticas públicas e normas jurídicas que retratem esse tema, já que as normas do SINASE, não são efetivadas em todas a unidade de internação, uma vez que não existe recorte de gênero.

O que se vê nos sistema socioeducativo ainda são: a desigualdade dos direitos das meninas frente aos direitos das meninos internados, a repressão do empoderamento feminino e da libertação de padrões opressores patriarcais ainda é uma forte característica do sistema em que as adolescentes internadas estão incluídas.

Desta maneira, se cria dentro das instituições de ressocialização ambientes em que a menina mulher perde a autonomia sobre seu corpo, onde a proteção integral não é efetiva e os direitos individuais desrespeitados a todo momento, como a falta de cuidados face a carência de pré-natais de qualidade, ligados a questão da maternidade, por exemplo, o que gera uma crescente da discriminação de gênero.

\section{Conclusão}

Constatou-se que a diversidade de gênero faz parte do cotidiano das unidades de São Paulo, porém, o preconceito com essas adolescentes em conflito com a lei, ainda se mostra presente desde os funcionários da Fundação Casa até órgãos do judiciário. Mesmo São Paulo sendo o estado com mais casas de internação feminina no Brasil, a realidade das meninas invisíveis continua precária, segundo o Relatório de Pesquisa do Conselho Nacional de Justiça (CNJ), realizado no ano de 2015, e, denominado "Dos espaços aos direitos: a realidade da ressocialização na aplicação das medidas socioeducativas de internação das adolescentes do sexo feminino em conflito com a lei nas cinco regiões", mostra que ainda existe um longo caminho a percorrer para se conquistar a igualdade das meninas dentro das unidades de internação, bem como, a necessidade de informação no que tange a questões de gênero.

A falta de conhecimento de funcionários sócioeducadores sobre as normas do SINASE, além dos resquícios de pré - concepções machistas que alguns carregam, também se tornam fatores consideráveis para não efetivação dos direitos das meninas dentro das instituições de 
internação, e, consequentemente para a violação das diversidades de gênero. Essa é invisibilidade em que as adolescentes são submetidas todos os dias, principalmente no que tange a carência de políticas públicas especificas para elas, o que relativiza o preceito fundamental da proteção integral. Situação preocupante visto as reais possibilidades para retirá-las da invisibilidade a que são submetidas.

\section{Referências}

BOURDIEU, Pierre. A dominação masculina. 3 ed. Rio de Janeiro: Bertrand Brasil, 2003. BRASIL. Estatuto da Criança e do Adolescente. Lei 8.069, de 13 de julho de 1990.

BRASIL. Panorama Nacional a Execução de Medidas Socioeducativas de Internação. Conselho Nacional de Justiça (CNJ), 2012.

BRASIL. Conselho Nacional do Ministério Público. Relatório da Infância e Juventude - Resolução no 67/2011: Um olhar mais atento às unidades de internação e semiliberdade para adolescentes. Brasília: Conselho Nacional do Ministério Público, 2013.

BRASIL. Dos espaços aos direitos: a realidade da ressocialização na aplicação das medidas socioeducativas de internação das adolescentes do sexo feminino em conflito com a lei nas cinco regiões. Conselho Nacional de Justiça (CNJ), 2015.

BRASIL. Conselho Nacional de Justiça. Panorama Nacional: a execução das medidas socioeducativas de internação. Programa Justiça ao Jovem Brasília. CNJ, 2012.

BRASIL. Secretaria Nacional de Promoção dos Direitos da Criança e do Adolescente. Levantamento Nacional do Atendimento Socioeducativo ao Adolescente em Conflito com a Lei - 2010. Brasília, 2011.

CARVALHO, Salo. Criminologia, Garantismo e Teoria Crítica dos Direitos Humanos: Ensaio sobre o exercício dos poderes punitivos. In: Teoria Crítica dos Direitos Humanos no século XXI, pp. 476-522. 
DAVIS, Angela, DENT, Gina. A prisão como fronteira: gênero, globalização e punição. In: Estudos Feministas, pp. 523-531.

ESPINOZA, Olga. A mulher encarcerada em face do poder punitivo. São Paulo, IBCCRIM, 2004.

FOUCAULT, Michel. Vigiar e Punir: História da Violência nas prisões. Petrópolis: Vozes, 1988. Segunda parte Capítulo 1 A punição generalizada. Terceira parte "Disciplina”. Capítulo 1 e 2 p. P.69-93 e 125-172, respectivamente.

LEMGRUBER, Julita. Cemitério dos vivos: análise sociológica de uma prisão de mulheres. 2 ed Rio de Janeiro: Forense, 1999.

LIMA, F. S.; Veronese J. R. P. O Sistema Nacional de Atendimento Socioeducativo (SINASE): breves considerações. Rev. Bras. Adolescência e Confitualidade, 1(1): 29- 46, 2009.

MISSE, Michel. Violência, crime e corrupção: conceitos exíguos, objeto pleno. in José Vicente Tavares dos Santos e Alex Niche Teixeira, orgs.

SANTOS, Boaventura. Concepção Multicultural dos direitos humanos.2002.

SILVA, José Afonso da. Curso de Direito Constitucional Positivo. São Paulo: Malheiros, 2015.

SMART, Carol. Women, Crime and Criminology: A feminist critique. pp. 54-76; 108-145 176-185;

SOUZA, Tatiana. Análise discursiva da linguagem retórica punitiva de crianças e adolescentes infratores: linguagem e poder. Revista de Direito Candido Mendes $n^{0} 18$. 2013. Rio de janeiro. P. 1-20. 


\section{"Invisible Girls": The Reality of Adolescents' Ressocialization in the City of São Paulo}

ABSTRACT: The article makes a bibliographic study based on the Research Report of the National Council of Justice (CNJ / 2015), entitled "From spaces to rights: the reality of resocialization in the application of socioeducational measures for the admission of female adolescents in conflict with the law in Five regions. The objective is to make a critical analysis of the reality of the resocialization of girls in conflict in the city of São Paulo, aiming at understanding the day-to-day of adolescents during the fulfillment of socioeducative measures of hospitalization, also revealing that in many cases these are inserted in units Unprepared to receive them, which evidences the neglect of the State in the face of public policies focused on gender specificities. Therefore it is necessary to reflect on the discourses stigmatizastes in the life of the adolescents. In the meantime, we must emphasize that criminal policy is based on cruel practices, through symbolic violence, to execute its power in layers of the population that are usually: the poorest layers of citizens, blacks, and women. Thus, "invisible" girls suffer daily racism and prejudice, both by society and by the very law that punishes them, since they are discriminated against for the sole reason that they are women; Evidencing that the committing of infractions by the adolescents and the socio-educational measures applied, exceed the limits imposed by the laws applied by the judiciary.

KEYWORDS: Girls. Internship. Socioeducation. São Paulo. Gender.

Tatiana Lourenço Emmerich de SOUZA

Bacharel em Direito pela Universidade Candido Mendes. Advogada. Pós Graduada em Direito Penal Econômico e Europeu, pelo Instituto de Direito Penal Econômico e Europeu IDPEE, da Faculdade de Direito da Universidade de Coimbra em parceria com o Instituto Brasileiro de Ciências Criminais IBCCRIM. Mestre pela

Universidade Federal do Estado do Rio de Janeiro pelo Programa de Pós

Graduação em Politicas Públicas em Direitos Humanos (UFRJ / PPDH) Pesquisadora do Grupo de Pesquisas Matrizes Autoritárias do Processo Penal Brasileiro: A Prova Penal e o Sistema de Controles Epistêmicos. (Faculdade Nacional de Direito - LADIH/UFRJ). 